E3S Web of Conferences 1, 08007 (2013)

DOI: $10.1051 / \mathrm{e} 3$ sconf/20130108007

(c) Owned by the authors, published by EDP Sciences, 2013

\title{
Heavy Metals Levels in Soil and Vegetables in Different Growing Systems
}

\author{
C. Hura ${ }^{1}$, N. Munteanu ${ }^{2}$ and V. Stoleru ${ }^{2}$ \\ ${ }^{1}$ INSP/ Centre Regional of Public Health, Str.V.Babes nr.14, Iasi, Romania, carmen_hura@yahoo.com \\ ${ }^{2}$ University of Agricultural Sciences and Veterinary Medicine Iasi, Romania, nmunte@uaiasi.ro
}

\begin{abstract}
The current project deals with an issue of actuality and scientific/technical necessity and aims to assess the factors contributing to the vulnerability of ecological systems and therefore endangering/compromising food safety. The goals of this ongoing study are to address the main risk factors on ecological system with particular regards to fresh growing vegetables and to establish technical monitoring system(s) with a view to increase food safety. Herein, the authors present the research results obtained in 2011 in SIECOLEG Project regarding the assessment of some heavy metals (mainly lead, cadmium, cooper, and manganese) of 80 samples soils and 25 samples vegetables from some ecological system. The concentrations of heavy metals were measured by Atomic absorption spectrometer (AAS Schimadzu 6300) - with graphite furnace atomizer and autosampler. In soil: lead and cadmium concentrations ranged from 4.51 to $6.58 \mathrm{mg} / \mathrm{kg}$ and from 0.14 to $0.4 \mathrm{mg} / \mathrm{kg}$, respectively. Cooper and manganese concentrations ranged from 20.73 to 6.58 $\mathrm{mg} / \mathrm{kg}$ and from 218.1 to $298.3 \mathrm{mg} / \mathrm{kg}$, respectively. In vegetables (tomatoes, cucumber, peppers, eggplant, cabbage): lead concentrations ranged from 0.0 (tomatoes) to $4.35 \mathrm{mg} / \mathrm{kg}$ (cabbage); cooper concentrations ranged from $0.2 \mathrm{mg} / \mathrm{kg}$ (cucumber) to $0.80 \mathrm{mg} / \mathrm{kg}$ (eggplant); manganese concentrations ranged from 0.0 $\mathrm{mg} / \mathrm{kg}$ (tomatoes) to $0.60 \mathrm{mg} / \mathrm{kg}$ (eggplant). Cadmium was not detected in any of analysed vegetable samples. Under these circumstances, the project intends to demonstrate the extent of this vulnerability and to elaborate measures for controlling and diminishing the effects of the involved factors in order to increase food safety and security for ecological fresh vegetables
\end{abstract}

Key words: heavy metals, soil, vegetables, Romania

\section{Introduction}

Exposure to heavy metals is an important problem of environmental toxicology. Most of these metals are toxic to humans, animals and plants. Anthropogenic activities are the major sources of heavy metals redistribution. Man, being at the top of the food chain, is at great risk of suffering from health hazards associated with toxic metals because of bioaccumulation. From the sanitary point of view the presence of all alien substances in food products raises many problems because, with few exceptions, these substances have a certain level of toxicity, $[1,2,3,4,5]$. The levels of the concentrations of these compounds in food are regulated by the sanitary legislation of each country (Directive European).

The goals of this ongoing study are to address the main risk factors on ecological system with particular regards to fresh growing vegetables and to establish technical monitoring system(s) with a view to increase food safety. Herein, the authors present the research results obtained in 2011 in SIECOLEG Project regarding the assessment of some heavy metals (mainly lead, cadmium, cooper, and manganese) of soils and vegetables from some growing systems.

\section{Materials and Methods}

In 2011, in SIECOLEG project, on the assessment of heavy metals (lead, cadmium, copper, zinc, manganese), from 80 soil samples and 25 vegetables samples from different systems cultivation (organic, in conversion, conventional). Determination of heavy metals in different matrices was performed by atomic absorption spectrometry (AAS) - Schimadzu 6300, graphite furnace and autosampler.

\section{Results}


Table 1. The mean heavy metals levels in soil samples, 2011 (mg/kg)

\begin{tabular}{|l|l|c|c|c|c|c|c|}
\hline & \multicolumn{1}{|c|}{ Farm } & Nr.samples & Pb & Cd & Cu & Zn & Mn \\
\hline \multirow{3}{*}{ organic } & USAMV Iasi & 9 & 4.51 & 0.14 & 31.1 & 48.40 & 252.8 \\
\cline { 2 - 8 } & SCDL Bacau & 6 & 5.82 & 0.4 & 31.75 & 49.33 & 298.3 \\
\hline \multirow{2}{*}{ in conversion } & Andrieseni & 11 & 4.09 & 0.2 & 20.73 & - & - \\
\hline & greenhouse Roman & 8 & 6.58 & 0.23 & 25.62 & 40.75 & 282.1 \\
\cline { 2 - 8 } & Tg. Frumos & 14 & 6.04 & 0.23 & 27.21 & 57.17 & 218.9 \\
\cline { 2 - 8 } & Matca & 11 & 6.5 & 0.18 & 31.59 & 52.86 & 286.0 \\
\hline
\end{tabular}

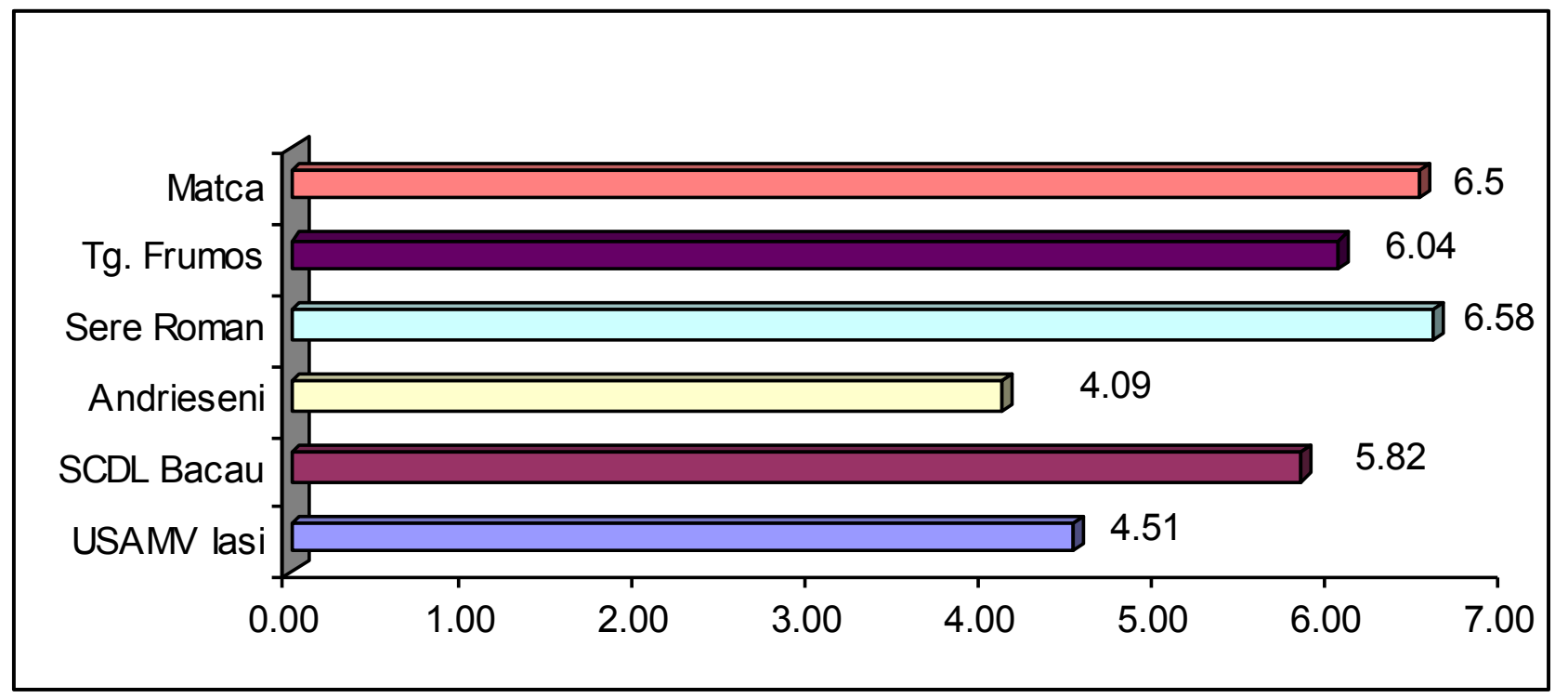

Fig. 1. The mean Plumb levels in soil samples, 2011, mg/kg

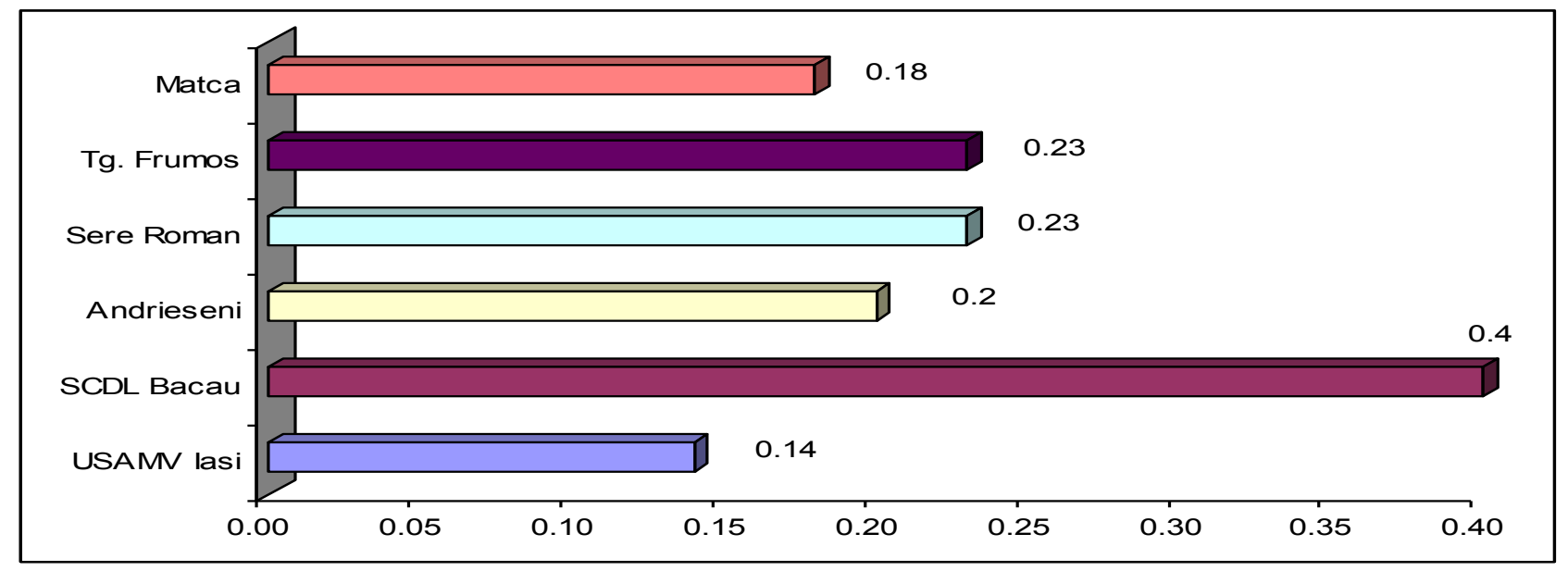

Fig. 2. The mean Cadmium levels in soil samples, 2011, mg/kg

Heavy metals levels in soil samples

Table 1 presents the mean levels of metals $(\mathrm{Pb}, \mathrm{Cd}, \mathrm{Cu}$, $\mathrm{Zn}, \mathrm{Mn}$ ) from soil analyzed in 2011 in some different growing systems (organic, in conversion, conventional). The mean levels of Lead varied between $4.09 \mathrm{mg} / \mathrm{kg}$ (farm Andrieseni - in conversion) and $6.58 \mathrm{mg} / \mathrm{kg}$ (greenhouse Roman - conventional) - Fig 1. The mean levels of Cadmium varied between $0.14 \mathrm{mg} / \mathrm{kg}$ (farm USAMV -organic) and $0.4 \mathrm{mg} / \mathrm{kg}$ (farm SCDL Bacau organic) - Fig 2. The mean levels of Cooper varied between $20.75 \mathrm{mg} / \mathrm{kg}$ (farm Andrieseni - in conversion) and $31.75 \mathrm{mg} / \mathrm{kg}$ (farm SCDL Bacau - organic) - Fig 3 . The mean levels of $\mathrm{Zn}$ varied between $40.75 \mathrm{mg} / \mathrm{kg}$ (greenhouse Roman - convetional) and $57.17 \mathrm{mg} / \mathrm{kg}$ (farm Tg.Frumos) and the mean levels of Mn varied 
Table 2. The mean heavy metals levels in vegetable samples, farm SCDL Bacau 2011 (mg/kg). nd = undectable.

\begin{tabular}{|l|c|c|c|c|c|}
\hline \multicolumn{1}{|c|}{ Vegetables } & Pb & Cd & Cu & Zn & Mn \\
\hline Tomatoes Siriona F1 & nd & nd & 0.5 & 1.45 & nd \\
\hline Tomatoes Unibac & nd & nd & 0.5 & 1.1 & nd \\
\hline Pepper "Siret" & 0.35 & nd & 0.7 & 1.9 & 0.35 \\
\hline Eggplant Epic & 0.6 & nd & 1.1 & 3.4 & 0.6 \\
\hline
\end{tabular}

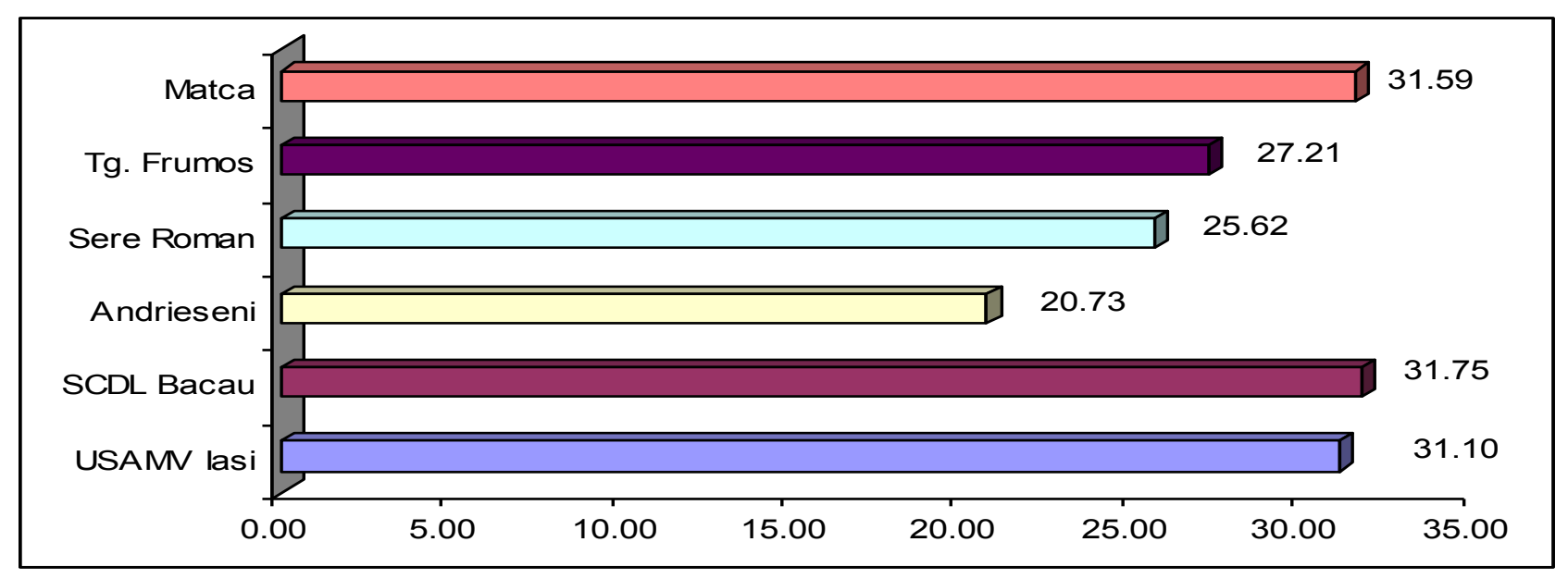

Fig. 3. The mean Cooper levels in soil samples, 2011, $\mathrm{mg} / \mathrm{kg}$

Table 3. The mean heavy metals levels in vegetable samples grown in conventional soil, 2011 (mg/kg)

\begin{tabular}{|c|c|c|c|c|c|c|}
\hline Farm & vegetable & $\mathbf{P b}$ & Cd & $\mathbf{C u}$ & $\mathbf{Z n}$ & $\mathrm{Mn}$ \\
\hline \multirow[t]{3}{*}{ Tg. Frumos/ Maxim } & Tomatoes Caliope & nd & nd & 0.35 & 0.6 & nd \\
\hline & Cucumber Meringue & 0.3 & nd & 0.55 & 1.1 & 0.3 \\
\hline & Pepper Mara Dona & nd & nd & .04 & 1.2 & nd \\
\hline \multirow[t]{3}{*}{ Tg.Fromos/Vavilov } & Tomatoes Bella & nd & nd & 0.45 & 1.0 & nd \\
\hline & Cucumber Meringue & 0.1 & nd & 0.2 & 1.25 & 0.1 \\
\hline & Pepper Vedrana & 0.1 & nd & 0.45 & 1.45 & 0.1 \\
\hline \multirow[t]{7}{*}{ Matca } & Tomatoes & nd & nd & 0.55 & 1.1 & nd \\
\hline & Tomatoes Winova & nd & nd & 0.6 & 1.0 & nd \\
\hline & Pepper Fidelio & nd & nd & 0.06 & 0.65 & nd \\
\hline & Tomatoes magnus & 0.45 & nd & 0.65 & 0.80 & 0.45 \\
\hline & Cucumber Michaela & nd & nd & 0.65 & 1.45 & nd \\
\hline & Tomatoes Magnus & nd & nd & 0.55 & 0.80 & nd \\
\hline & Cucumber Mirabella & nd & nd & & 1.25 & nd \\
\hline
\end{tabular}

between $218.9 \mathrm{mg} / \mathrm{kg}$ (farm Tg.Frumos) and $298.3 \mathrm{mg} / \mathrm{kg}$ (farm SCDL Bacau - organic).

\section{Heavy metals levels in vegetable samples}

The mean heavy metals levels ( $\mathrm{Pb}, \mathrm{Cd}, \mathrm{Cu}, \mathrm{Zn}, \mathrm{Mn}$ ) from vegetables (tomatoes, pepper, cucumber, eggplant, cabbage) analyzed in 2011, were present in Table 2, Table 3 and Table 4.

Table 2 presents the heavy metals levels $(\mathrm{Pb}, \mathrm{Cd}$, $\mathrm{Cu}, \mathrm{Zn}, \mathrm{Mn})$ in vegetable samples grown on organic soil from farm SCDL Bacau. In all vegetables analyzed (tomatoes, pepper, eggplant) not detected cadmium and in tomatoes samples not detected lead and manganese. The contents of lead, cadmium, cooper, zinc and manganese were in admissible limits,in according with Europene Reglementation.

Table 3 presents the heavy metals levels $(\mathrm{Pb}, \mathrm{Cd}$, $\mathrm{Cu}, \mathrm{Zn}, \mathrm{Mn}$ ) in vegetable samples grown on conventional soil from farm Tg.Frumos and Matca. In all vegetables analyzed (tomatoes, pepper, cucumber) not detected cadmium and in tomatoes samples not detected lead and 
Table 4. The mean heavy metals levels in vegetable samples grown in conversion soil, 2011 (mg/kg). nd = undetectable.

\begin{tabular}{|c|l|c|c|c|c|c|}
\hline \multicolumn{1}{|c|}{ Farm } & \multicolumn{1}{|c|}{ vegetable } & Pb & Cd & Cu & Zn & Mn \\
\hline \multirow{5}{*}{ Andrieseni } & pepper & nd & nd & 0.65 & 1.0 & nd \\
\cline { 2 - 7 } & tomatoes & 0.25 & nd & 0.70 & 1.85 & 0.25 \\
\cline { 2 - 7 } & eggplant & 0.30 & nd & $\mathbf{0 . 8 0}$ & 1.55 & 0.30 \\
\cline { 2 - 7 } & cucumber Meringue & nd & nd & 0.30 & 1.15 & nd \\
\cline { 2 - 8 } & onion & 0.55 & nd & 0.50 & 1.65 & 0.55 \\
\cline { 2 - 8 } & beans & 1.30 & nd & 0.65 & 3.35 & 1.30 \\
\cline { 2 - 8 } & cabbage & 4.35 & nd & 0.45 & 4.85 & 4.35 \\
\hline
\end{tabular}

manganese. The contents of lead varied between undetectable (tomatoes) and $0.45 \mathrm{mg} / \mathrm{kg}$ (tomatoes Magnus). The cooper levels varied between $0.2 \mathrm{mg} / \mathrm{kg}$ (cucumber Meringue) and $0.65 \mathrm{mg} / \mathrm{kg}$ (cucumber Michaela, tomatoes Magnus)

Table 4 presents the heavy metals levels $(\mathrm{Pb}, \mathrm{Cd}$, $\mathrm{Cu}, \mathrm{Zn}, \mathrm{Mn}$ ) in vegetable samples grown on in conversion soil from farm Andreseni. In all vegetables analyzed (tomatoes, pepper, cucumber,eggplant, beans, cabbage) not detected cadmium. The contents of lead varied between undetectable (pepper, cucumber Meringue) and $4.35 \mathrm{mg} / \mathrm{kg}$ (cabbage). The cooper levels varied between $0.3 \mathrm{mg} / \mathrm{kg}$ (cucumber Meringue) and 0.80 $\mathrm{mg} / \mathrm{kg}$ (eggplant).

\section{Conclusion}

1. The mean heavy metals levels ( $\mathrm{Pb}, \mathrm{Cd}, \mathrm{Cu}, \mathrm{Mn}, \mathrm{Zn})$ in soil and vegetable samples analyzed in 2011 were in the admissible limits in concordance with European Reglementations.

2. The project intends to demonstrate the extent of this vulnerability and to elaborate measures for controlling and diminishing the effects of the involved factors in order to increase food safety and security for ecological fresh vegetables

\section{References}

1. Lokeshwari H and Chandrappa G T, Curr Sci., 2006, 91(5), 584.

2. C. Hura, 2007 - Chemical contaminants in food in România, in 2006, vol. 6, Publishing House: CERMI, Iaşi, 2007 - ISBN: ISBN: 978-973-248-4.

3. C.Hura, B.A. Hura (2007) - Assessment of the heavy metals in the food from Romania, 2005 - 2006. International Congress of Toxicology (ICT XI), 15 19. 07.2007, Montreal, Canada.

4. C. Hura, 2009 - Chemical contaminants in food and human body -Publishing House: CERMI, Iaşi, 2009 - ISBN: 978-973- 667-364-1-

5. Rajesh Kumar Sharma,et.al.(2007) - Heavy metal contamination of soil and vegetables in suburban areas of Varanasi, India - Ecotoxicology and Environmental Safety ,Volume 66, Issue 2, Pages 258-266. 